\title{
EVALUATION OF FETAL THIGH CIRCUMFERENCE AS AN ADDITIONAL MARKER FOR FOETAL BIOMETRY
}

\author{
SARYU GUPTA ${ }^{1}$, BHARDWAJ ${ }^{1}$, PARAMJEET KAUR ${ }^{2}$, PUNEET GAMBHIR ${ }^{3 *}$ \\ ${ }^{1}$ Department of Radiodiagnosis, Government Medical College and Rajindra Hospital Patiala, Patiala, Punjab, India. ${ }^{2}$ Department \\ of Obstetrics and Gynaecology, Government Medical College and Rajindra Hospital Patiala, Patiala, Punjab, India. ${ }^{3}$ Department of \\ Community, Medicine Government Medical College and Rajindra Hospital Patiala, Patiala, Punjab, India. Email: drpuneetgmc@gmail.com
} Received: 20 June 2021, Revised and Accepted: 26 July 2021

\section{ABSTRACT}

Objective: Accurate determination of gestational age is the sine qua non of optimal management and hence prognostication of all pregnancies.A meticulous biometry ensures timely interventions resulting in favorable maternal and fetal outcomes. Traditionally, the parameters of Biparietal diameter (BPD), Femur length (FL), Head circumference (HC), and Abdominal circumference (AC) have been utilized for routine fetal biometry. The present study aims to assess the utility of Fetal Thigh Circumference (ThC) as an additional marker for fetal biometry.

Methods: The present retrospective, observational, and cross-sectional study was done in the Departments of Radiodiagnosis and Obstetrics and Gynaecology in an ethically and socio-economically diverse group of pregnant females. All pregnant females with singleton pregnancies between 22 and 40 weeks of gestation and fulfilling the inclusion and exclusion criteria were subjected to ultrasound examination. Subsequently analysis was done for the data collected.

Results: There were a total of 287 participants in present study group with mean age of $23 \pm 3.4$ years. The strength of agreement almost perfect ( $>0.99$ ) between the mean observed ThC to ThC values by Deter et al. taken as standard. There was a highly significant positive correlation between gestational period and standard biometry parameters and ThC. ThC model for prediction will be better than standard biometry parameters of BPD, HC and AC but not as good as FL model according to the regression analysis of the present study.

Conclusions: There is concordance of fetal ThC as an accurate predictor of period of gestation only after FL. It can be combined with standard biometry parameters to give a better estimation of period of gestation.

Keywords: Fetal biometry, Fetal thigh circumference, Ultrasound, Gestational age.

(c) 2021 The Authors. Published by Innovare Academic Sciences Pvt Ltd. This is an open access article under the CC BY license (http://creativecommons.org/ licenses/by/4.0/) DOI: http://dx.doi.org/10.22159/ajpcr.2021v14i9.42646. Journal homepage: https://innovareacademics.in/journals/index.php/ajpcr

\section{INTRODUCTION}

Ultrasound imaging remains the modality of choice for assessment of the pregnant woman despite scientific developments and technology advancing by leaps and bounds over the past many years. Despite the complete transformative and in-depth experience offered by ultrasound as a modality per se due to the exceptional output now available with the current high-end machines, evaluation of fetal growth remains the crux for planning all intervention and management related strategies. The importance of accurate fetal biometry hence cannot be overemphasized. The conventional fetal growth parameters for this purpose have primarily included Biparietal Diameter (BPD), Femur length (FL), Head circumference (HC), and Abdominal circumference (AC). The most common parameters used for fetal growth evaluation include BPD and FL [3] while some of the other additional parameters used on a case to case basis by some of the researchers include the transcerebellar diameter (TCD) [4], Fetal renal length and/or volume [5-7], humeral length, scapular length [8], and multiple fetal parameters [9] besides others.

Fetal Thigh Circumference (ThC) reflects the soft tissue mass as concluded in various pediatric studies and hence an attempt was made in the present study to assess its application as an additional biometric parameter.

\section{Aim}

The aim of the study was to determine the diagnostic accuracy of fetal $\mathrm{ThC}$ as an additional marker for fetal biometry.

\section{MATERIALS AND METHODS}

This study was conducted jointly by the Departments of Radiodiagnosis and Obstetrics and Gynaecology of tertiary level institute, Government Medical College and Rajindra Hospital, Patiala.

\section{Study design}

This is a retrospective, observational, cross-sectional, and single - institution study.

\section{Study period}

1 year.

\section{Study population}

All pregnant females with singleton pregnancies and fulfilling all the inclusion and the exclusion criteria were included in the present study.

\section{Inclusion/Exclusion criteria}

It included only uncomplicated pregnancies that is with no evidence of maternal comorbidities (Hypertension, Diabetes Mellitus, thyroid disorders, anemia or any other known pathology) or fetal compromise (all fetuses with evidence of proven abnormalities in the present pregnancy as intrauterine growth retardation and/or congenital malformation) were excluded from the study and had given informed consent for the study.

\section{Methodology}

Each patient was counted as only once in the data base even if they were examined multiple times during the pregnancy. 
Table 1: Mean thigh circumference observed values of study compared with corresponding values by Deter et al. [1,2,13]

\begin{tabular}{|c|c|c|c|c|c|c|}
\hline \multirow[t]{2}{*}{ Period of gestation in weeks } & \multirow[t]{2}{*}{ Obs. } & \multicolumn{4}{|c|}{ ThC in $\mathbf{m m}$} & \multirow[t]{2}{*}{ ThC by Deter et al. } \\
\hline & & Mean & Standard deviation & Confidence limit lower & Confidence limit upper & \\
\hline 22 & 11 & 66.05 & 6.72 & 52.61 & 79.48 & 71.00 \\
\hline 24 & 19 & 82.58 & 8.24 & 66.10 & 99.05 & 83.00 \\
\hline 25 & 16 & 87.80 & 10.75 & 66.30 & 109.30 & 89.00 \\
\hline 26 & 16 & 97.06 & 9.50 & 78.05 & 116.07 & 95.00 \\
\hline 27 & 15 & 95.37 & 9.21 & 76.94 & 113.79 & 100.00 \\
\hline 28 & 20 & 105.13 & 8.93 & 87.26 & 122.99 & 106.00 \\
\hline 29 & 21 & 114.79 & 9.96 & 94.87 & 134.70 & 112.00 \\
\hline 30 & 16 & 119.00 & 10.61 & 97.77 & 140.23 & 118.00 \\
\hline 31 & 15 & 118.00 & 12.51 & 92.97 & 143.03 & 124.00 \\
\hline 32 & 19 & 130.26 & 11.48 & 107.30 & 153.23 & 130.00 \\
\hline 33 & 14 & 132.71 & 13.74 & 105.23 & 160.20 & 135.00 \\
\hline 34 & 16 & 135.84 & 14.37 & 107.10 & 164.59 & 141.00 \\
\hline 35 & 21 & 143.26 & 14.31 & 114.64 & 171.88 & 147.00 \\
\hline 36 & 21 & 157.36 & 16.86 & 123.63 & 191.09 & 153.00 \\
\hline 38 & 8 & 166.00 & 14.29 & 137.42 & 194.58 & 164.00 \\
\hline 39 & 4 & 180.00 & 26.02 & 127.96 & 232.04 & 170.00 \\
\hline 40 & $1^{*}$ & 180.00 & & & & 176.00 \\
\hline
\end{tabular}

*Single case hence Mean and SD not calculated. ThC: Thigh circumference

Ultrasound examination was carried out and measurements included those of BPD, HC, FL, and AC; all measured as per standardized protocols. BPD was measured as described by for measurement of the Fetal ThC the level was selected as at the junction of the upper and middle thirds of the thigh where a change in femur profile shape could be detected, by direct measurement. To measure the ThC the long axis of the femur was imaged first and then the transducer rotated 90 degrees to obtain a cross-sectional profile at the junction of the upper and middle thirds of the thigh at a position that the bone profile was as round as possible and the boundary of the thigh profile was well defined. Two readings were taken by the same operator in each image so as to rule out intra-observer variation.

\section{Statistical analysis}

Data collection and analysis were done using Microsoft Excel with Xrealstats add on [10], Epi info version 7.2.4.0 (CDC Atlanta) [11], and Medcalc Statistical version 20.006 [12]. Parametric and non-parametric methods were used especially Descriptive analysis, Concordance Correlation Coefficient, Pearson correlation coefficient, and Regression analysis $\mathrm{R}^{2}$ were calculated to evaluate how $\mathrm{ThC}$ and other traditionally standard biometry parameters fetal growth assessment parameters of BPD, HC. AC and FL correlates with gestational age.

\section{RESULTS}

There were a total of 287 participants in present study group with mean age of $23 \pm 3.4$ years. The youngest member was 18 years and oldest was 32 years of age. The gestation age at ultrasound examination of the selected subjects ranged from 22 weeks to 40 weeks.

The mean ThC for each week was calculated and compared with the values as predicted by Deter et al. [1,2,13]

The present study shows an increase in ThC with increase in gestational age from 22 week to 40 weeks except for 37 weeks where it has shown a small decrease. The increase was found to be statistically significant (ANOVA, p<0.0001)

The strength of agreement as shown by Concordance correlation coefficient was almost perfect $(>0.99)$ between the mean observed ThC to values by Deter et al. $[1,2,13]$. The precision and accuracy were also almost perfect (Tables 2 and 3 ).

Table 4 shows the mean of standard biometry parameters (including BPD, HC, AC, and FL) and ThC; along the number of cases examined in each week of gestational period.
Table 2: Concordance correlation coefficient of mean observed thigh circumference to values by Deter et al.

\begin{tabular}{ll}
\hline Concordance correlation coefficient & 0.9914 \\
95\% Confidence interval & $0.9792-0.9965$ \\
Pearson $\rho$ (precision) & 0.9926 \\
Bias correction factor Cb (accuracy) & 0.9987 \\
\hline
\end{tabular}

Table 3: Descriptive scale for values of the concordance correlation coefficient (Mc Bride) [14-16]

\begin{tabular}{ll}
\hline Value of $\boldsymbol{\rho}_{\mathbf{c}}$ & Strength of agreement \\
\hline$<0.90$ & Poor \\
$0.90-0.95$ & Moderate \\
$0.95-0.99$ & Substantial \\
$>0.99$ & Almost perfect \\
\hline
\end{tabular}

Observation Table 5 showed that there was a highly significant positive correlation between gestational period and standard biometry parameters FL ( $\mathrm{r}=0.9950), \mathrm{HC}(\mathrm{r}=0.9906), \mathrm{BPD}(\mathrm{r}=0.9904)$, and AC $(r=0.9850)$.

ThC ( $r=0.9927)$ also shows a similar highly positive significant correlation; better than HC, BPD, and AC.

Regression analysis was done to describe the relationship of gestational period with standard biometry parameters and ThC; besides to predict the gestational period through them, that is, gestational period is the dependent variable while standard biometry parameters and ThC are the independent variables.

Regression analysis (Table 6 and Fig. 2) confirms there was a significant correlation between gestational period (weeks) and standard biometry parameters $(\mathrm{mm})$ mean of FL $\left(\mathrm{r}^{2}=0.990\right)(\mathrm{p}<0.0001)$, BPD $\left(\mathrm{r}^{2}=0.981\right)$ $(\mathrm{p}<0.0001), H C\left(\mathrm{r}^{2}=0.971\right)(\mathrm{p}<0.0001)$, and AC $\left(\mathrm{r}^{2}=0.970\right)(\mathrm{p}<0.0001)$.

ThC (mm) showed a similar highly significant correlation between gestational period (weeks) with $\mathrm{r}^{2}=0.986$ better than BPD, HC, and AC.

Residual standard deviation is the standard deviation of the residual values, or the difference between a set of observed and predicted values. The smaller the residual standard deviation is compared to the sample standard deviation, the more predictive, or useful, the model is [17]. 
Table 4: USG measurement of known parameters and calculated ThC

\begin{tabular}{|c|c|c|c|c|c|c|c|c|c|c|c|}
\hline \multicolumn{2}{|l|}{ Parameters $\rightarrow$} & \multicolumn{2}{|c|}{ BPD in $\mathbf{m m}$} & \multicolumn{2}{|c|}{$\mathrm{HC}$ in $\mathrm{mm}$} & \multicolumn{2}{|c|}{$\mathrm{AC}$ in $\mathrm{mm}$} & \multicolumn{2}{|c|}{ FL in $\mathbf{m m}$} & \multicolumn{2}{|c|}{ ThC in $\mathbf{m m}$} \\
\hline Gestational period in weeks & No. of cases & Mean & Std. dev. & Mean & Std. dev. & Mean & Std. dev. & Mean & Std. dev. & Mean & Std. dev. \\
\hline 22 & 11 & 56.09 & 1.22 & 200.27 & 3.17 & 178.00 & 1.26 & 38.64 & 0.81 & 66.05 & 6.72 \\
\hline 24 & 20 & 63.10 & 0.97 & 222.90 & 3.73 & 198.15 & 4.46 & 44.00 & 1.12 & 82.58 & 8.24 \\
\hline 25 & 15 & 66.60 & 1.92 & 233.93 & 1.98 & 211.73 & 2.09 & 46.33 & 1.50 & 87.80 & 10.75 \\
\hline 26 & 16 & 69.81 & 1.28 & 245.69 & 4.01 & 219.94 & 2.54 & 49.00 & 0.82 & 97.06 & 9.50 \\
\hline 27 & 15 & 72.40 & 1.76 & 251.60 & 3.25 & 231.33 & 3.18 & 50.93 & 0.96 & 95.37 & 9.21 \\
\hline 28 & 20 & 73.90 & 1.92 & 256.65 & 2.56 & 234.30 & 4.68 & 53.20 & 1.20 & 105.13 & 8.93 \\
\hline 29 & 21 & 76.10 & 1.67 & 266.48 & 4.37 & 244.38 & 3.54 & 55.95 & 0.80 & 114.79 & 9.96 \\
\hline 30 & 16 & 77.94 & 2.59 & 270.50 & 3.54 & 247.13 & 6.78 & 56.69 & 1.30 & 119.00 & 10.61 \\
\hline 31 & 15 & 77.47 & 1.30 & 272.93 & 5.06 & 252.73 & 7.60 & 56.73 & 2.46 & 118.00 & 12.51 \\
\hline 32 & 19 & 82.47 & 3.69 & 283.58 & 5.08 & 263.00 & 3.07 & 61.53 & 1.02 & 130.26 & 11.48 \\
\hline 33 & 14 & 85.57 & 2.34 & 298.57 & 8.76 & 269.21 & 4.63 & 63.79 & 1.19 & 132.71 & 13.74 \\
\hline 34 & 16 & 85.25 & 3.02 & 306.94 & 6.31 & 274.19 & 2.83 & 66.63 & 0.50 & 135.84 & 14.37 \\
\hline 35 & 21 & 87.62 & 1.20 & 315.05 & 3.88 & 311.19 & 5.28 & 68.14 & 0.65 & 143.26 & 14.31 \\
\hline 36 & 21 & 89.71 & 1.71 & 319.57 & 2.09 & 315.67 & 2.13 & 70.33 & 0.58 & 157.36 & 16.86 \\
\hline 38 & 8 & 93.00 & 2.56 & 328.25 & 3.88 & 318.75 & 1.39 & 73.88 & 1.13 & 166.00 & 14.29 \\
\hline 39 & 4 & 94.50 & 1.00 & 338.50 & 1.91 & 319.50 & 1.00 & 74.00 & 0.82 & 180.00 & 26.02 \\
\hline 40 & 1 & 96.00 & & 330.00 & & 320.00 & & 75.00 & & 180.00 & \\
\hline
\end{tabular}

BPD: Biparietal diameter, FL: Femur length, HC: Head circumference, AC: Abdominal circumference, ThC: Thigh circumference

Table 5: Correlation coefficient with gestational period

\begin{tabular}{llll}
\hline Parameter & $\begin{array}{l}\text { Correlation } \\
\text { coefficient } \mathbf{r}\end{array}$ & $\begin{array}{l}\mathbf{9 5 \%} \text { confidence } \\
\text { interval for } \mathbf{r}\end{array}$ & p-value \\
\hline BPD & 0.9904 & $0.9747-0.9964$ & $<0.0001$ \\
HC & 0.9906 & $0.9751-0.9964$ & $<0.0001$ \\
AC & 0.9850 & $0.9605-0.9943$ & $<0.0001$ \\
FL & 0.9950 & $0.9867-0.9981$ & $<0.0001$ \\
ThC & 0.9927 & $0.9807-0.9973$ & $<0.0001$ \\
\hline
\end{tabular}

BPD: Biparietal diameter, FL: Femur length, HC: Head circumference,

AC: Abdominal circumference, ThC: Thigh circumference

Hence, the regression analysis shows the predictive value of gestational age to be best with FL (Res. Std. dev=0.579), ThC (Res. Std. dev=0.698), BPD (Res. Std. dev=0.800), HC (Res. Std. dev=0.991), and AC (Res. Std. dev=0.999). ThC model for prediction will be better than standard biometry parameters of BPD, HC, and AC but not as good as FL model according to the regression analysis of the present study.

\section{DISCUSSION}

To forget and recall is human nature. The gestational period depending on recall of its last menstrual period often makes the whole concept dicey for the assessment and management of fetus. In a study by Campbell et al. $45 \%$ of participants were uncertain about their menstrual dates attributed to poor recall, irregular cycles, contraceptive use, and bleeding in early pregnancy [18]. In the past, a few days of inaccuracy was probably acceptable; but now emerging data suggest that a few days inaccuracy can affect things, such as the performance of maternal serum screening, the assessment of post-dates pregnancy, and the subsequent induction of labour [19].

The choice of parameter (keeping in view that more than one fetal measurement to predict menstrual age is required to predict age in a given case) should depend on the number of technically satisfactory measurements obtained [9]. Besides biological variation in size is less during the first trimester than in the third trimester. Ultrasound estimation of gestational age in the first trimester is therefore more accurate than later in pregnancy [20].

Thus, the focus is on a parameter that is stands the growth pattern irrespective of overall growth pattern of pregnancy. Standard biometry

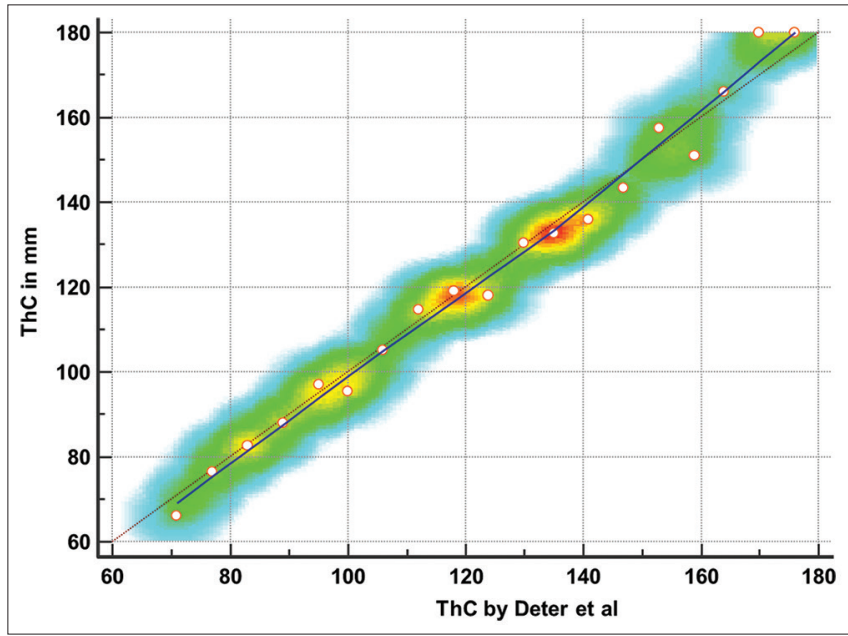

Fig. 1: Scatter diagram of observed mean thigh circumference (ThC) and ThC by Deter et al. considered standard

parameters have their own limitations such as BPD and HC have molding of head in $3^{\text {rd }}$ trimester and hydrocephalus, FL in achondroplasia and AC in ascites [9,21]. At present, studies are showing TCD to be a reliable parameter at the end of second trimester [4,21-23] but still a long way to go.

Hence, it becomes imperative that the fetus period of gestation is accurately estimated with lesser reliability on recall history superadded by biological variability and technical satisfactory measurements. The study attempted to revisit the use of ThC as an additional biometry parameter.

In the current study, the mean ThC values was compared with ThC readings by Deter et al. who were considered standard (Table 1). There was a very high degree of agreement with the actual values and the standard values (Fig. 1). This part of the study was an attempt to see the accuracy of measurement to ensure technical satisfactory measurements.

Among the standard biometry parameters used in estimation of period of gestation FL was found to be the most accurate one. All these parameters showed an increase with an increase in period of gestation 

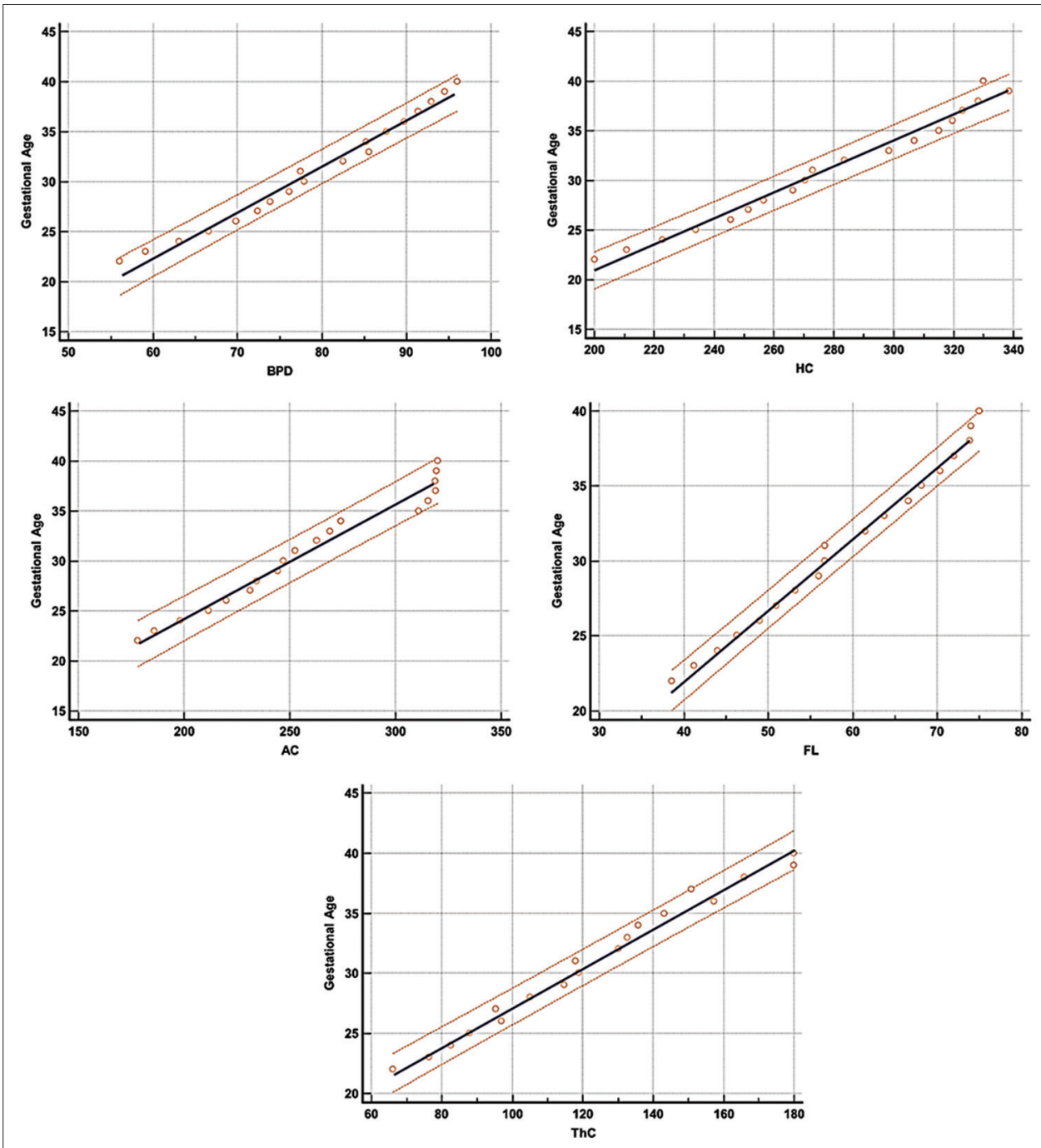

Fig. 2: Linear regression of mean standard biometry parameters (in $\mathrm{mm}$ ) and mean thigh circumference (in mm) and period of gestation (in weeks), showing scatter diagram between $95 \%$ prediction levels

Table 6: Regression analysis shows predicted values of independent parameters BPD, HC, AC, FL, and ThC with dependent variable of gestational period in weeks

\begin{tabular}{|c|c|c|c|c|c|c|c|c|c|c|}
\hline \multirow[t]{2}{*}{ Parameters } & \multicolumn{2}{|l|}{ Intercept } & \multicolumn{2}{|l|}{ Slope } & \multicolumn{2}{|l|}{ p-value } & \multicolumn{2}{|l|}{$95 \% \mathrm{CI}$} & \multirow[t]{2}{*}{$\mathbf{R}^{2}$} & \multirow{2}{*}{$\begin{array}{l}\text { Residual } \\
\text { std. } \\
\text { deviation }\end{array}$} \\
\hline & Coefficient & Std. Error & Coefficient & Std. Error & Intercept & Slope & Intercept & Slope & & \\
\hline BPD & -5.201 & 1.238 & 0.459 & 0.016 & 0.0006 & $<0.0001$ & $-7.813--2.589$ & $0.4264-0.492$ & 0.981 & 0.800 \\
\hline $\mathrm{HC}$ & -5.020 & 1.222 & 0.130 & 0.004 & 0.0007 & $<0.0001$ & $-7.599--2.441$ & $0.1205-0.139$ & 0.971 & 0.991 \\
\hline $\mathrm{AC}$ & 1.305 & 1.282 & 0.115 & 0.005 & 0.3228 & $<0.0001$ & $-1.3994-4.010$ & $0.1045-0.125$ & 0.970 & 0.999 \\
\hline FL & 3.066 & 0.694 & 0.475 & 0.012 & 0.0004 & $<0.0001$ & $1.6020-4.5293$ & $0.4503-0.499$ & 0.990 & 0.579 \\
\hline $\mathrm{ThC}$ & 10.960 & 0.612 & 0.163 & 0.005 & $<0.0001$ & $<0.0001$ & $9.6685-12.2504$ & $0.1527-0.1730$ & 0.986 & 0.698 \\
\hline
\end{tabular}

BPD: Biparietal diameter, FL: Femur length, HC: Head circumference, AC: Abdominal circumference, ThC: Thigh circumference

which was statistically significant; which was in concordance with most of the studies in the literature. Table 4 shows the different parameters of the present study, that is, BPD, HC, AC, FL, and ThC increase as the pregnancy increases.

When the individual observation of mean ThC was studied to period of gestation in weeks, the correlation coefficient was found to be 0.99 which was statistically highly significant.

The current study also deduced a ThC had a better correlation with period of gestation than BPD, HC, and AC, but lesser than FL.
Regression analysis confirmed a strong relationship of observed ThC and period of gestation. With increasing THC there was a statistically significant increase in period of gestation.

\section{CONCLUSIONS}

There is concordance of Fetal ThC as an accurate predictor of period of gestation only after FL. The current study observed that ThC increased linearly with period of gestation and $\mathrm{ThC}$ in $\mathrm{mm}$ was capable of predicting period of gestation with accuracy. It can be combined with standard biometry parameters to give a better estimation of period of gestation. 


\section{Particulars of contributors}

1. Associate Professor, Department of Radiodiagnosis, Government Medical College and Rajindra Hospital, Patiala, Punjab, India.

2. Ex-Professor and Head Department of Radiodiagnosis, Government Medical College and Rajindra Hospital, Patiala, Punjab, India.

3. Ex- Professor, Department of Gynaecology and Obstetrics, Government Medical College and Rajindra Hospital, Patiala, Punjab, India

4. Assistant Professor, Department of Community Medicine, Government Medical College.

\section{CONTRIBUTION OF AUTHORS}

Dr. Saryu Gupta, Associate professor, contributed in study design, data collection, analysis and preparation; Dr Bhardwaj Ex-head and Professor and Dr Paramjeet Kaur Ex-Professor conceptualized the idea, worked on discussions, conclusions, and reviewed manuscript and Dr Puneet Gambhir, Assistant Professor helped in analysis and final manuscript preparation.

\section{REFERENCES}

1. Deter RL, Warda A, Rossavik IK, Duncan G, Hadlock FP. Fetal thigh circumference: A critical evaluation of its relationship to menstrual age. J Clin Ultrasound 1986;14:105-10.

2. Deter RL, Rossavik IK, Cortissoz C, Hill RM, Hadlock FP. Longitudinal studies of thigh circumference growth in normal fetuses. J Clin Ultrasound 1987;15:388-93.

3. Egley CC, Seeds JW, Cefalo RC. Femur length versus biparietal diameter for estimating gestational age in the third trimester. Am J Perinatol 1986;3:77-9.

4. Chavez MR, Ananth CV, Smulian JC, Yeo L, Oyelese Y, Vintzileos AM. Fetal transcerebellar diameter measurement with particular emphasis in the third trimester: A reliable predictor of gestational age. Am J Obstet Gynecol 2004;191:979-84

5. Ansari SM, Saha M, Paul AK, Mia SR, Sohel A, Karim R. Ultrasonographic study of 793 foetuses: Measurement of normal foetal kidney lengths in Bangladesh. Australas Radiol 1997;41:3-5.

6. Kumar K, Beg MR, Babu CS, Shrivastava RK. Estimation of fetal gestational age in second and third trimesters from ultrasonographic measurements of different fetal biometric parameters. Indian J Clin Anat Physiol 2015;2:111-6.

7. Konje JC, Abrams KR, Bell SC, Taylor DJ. Determination of gestational age after the $24^{\text {th }}$ week of gestation from fetal kidney length measurements. Ultrasound Obstet Gynecol 2002;19:592-7.

8. Dilmen G, Turhan NO, Toppare MF, Seçkin N, Oztürk M, Göksin E. Scapula length measurement for assessment of fetal growth and development. Ultrasound Med Biol 1995;21:139-42.

9. Hadlock FP, Harrist RB, Shah YP, King DE, Park SK, Sharman RS. Estimating fetal age using multiple parameters: A prospective evaluation in a racially mixed population. Am J Obstet Gynecol 1987;156:955-7.

10. Zaiontz C. Real Statistics Using Excel Real Statistics Resource Pack software (Release 7.6); 2013-2021. Available from: https://www.realstatistics.com 2020.

11. Dean AG, Arner TG, Sunki GG, Friedman R, Lantinga M, Sangam S, et al. Epi Info ${ }^{\mathrm{TM}}$, a Database and Statistics Program for Public Health Professionals. Atlanta, GA, USA: CDC; 2011

12. MedCalc ${ }^{\circledR}$. Statistical Software Version 20.006. Ostend, Belgium: MedCalc Software Ltd.; 2021. Available from: https://www.medcalc.org.

13. Warda A, Deter RL, Duncan G, Hadlock FP. Evaluation of fetal thigh circumference measurements: A comparative ultrasound and anatomical study. J Clin Ultrasound 1986;14:99-103.

14. Lawrence IK. A concordance correlation coefficient to evaluate reproducibility. Biometrics 1989;45:255-68.

15. Liao JJ, Lewis JW. A note on concordance correlation coefficient. PDA J Pharm Sci Technol 2000;54:23-6.

16. McBride GB. A Proposal for Strength-of-Agreement Criteria for Lin's Concordance Correlation Coefficient, NIWA Client Report No. HAM2005-062; 2005. p. 1-10

17. Kenton KK. Residual Standard Deviation; 2020. Available from: https://www.investopedia.com/terms/r/residual-standard-deviation.asp.

18. Campbell S, Warsof SL, Little D, Cooper DJ. Routine ultrasound screening for the prediction of gestational age. Obstet Gynecol 1985;65:613-20.

19. Butt K, Lim K. Determination of gestational age by ultrasound. J Obstet Gynaecol Can 2014;36:171-81.

20. Caughey AB, Nicholson JM, Washington AE. First-vs second-trimester ultrasound: The effect on pregnancy dating and perinatal outcomes. Am J Obstet Gynecol 2008;198:703.e1-5; discussion 703.e5-6.

21. Cinnusamy M, Shastri D, Martina J. Estimation of gestational age by ultrasound measurement of fetal transcerebellar diameter. J Anat Soc India 2021;70:19-24

22. Chavez MR, Ananth CV, Smulian JC, Lashley S, Kontopoulos EV, Vintzileos AM. Fetal transcerebellar diameter nomogram in singleton gestations with special emphasis in the third trimester: A comparison with previously published nomograms. Am J Obstet Gynecol 2003;189:1021-5.

23. Meyer WJ, Gauthier DW, Goldenberg B, Santolaya J, Sipos J, Cattledge F. The fetal transverse cerebellar diameter/abdominal circumference ratio: A gestational age-independent method of assessing fetal size. J Ultrasound Med 1993;12:379-82. 